\title{
Populações serranas excluídas, cidades insustentáveis: o enigma da participação pública
}

\author{
Excluded mountain populations, unsustainable cities: \\ the enigma of public participation
}

Sergio Luiz Dias Portella ${ }^{1}$

João Arriscado Nunes ${ }^{2}$

\footnotetext{
${ }^{1}$ Presidência, Fundação Oswaldo Cruz. Av. Brasil 4365, Manguinhos. 21.040360 Rio de Janeiro RJ Brasil. sportella@fiocruz.br ${ }^{2}$ Centro de Estudos Sociais, Universidade de Coimbra.
}

\begin{abstract}
By highlighting the extreme event of 11-12 January 2011 in the mountain cities of the state of Rio de Janeiro, Brazil, an attempt is made to exemplify the triad paradigmatically: contemporary problems / government inability to adapt / low public participation, and highlight the issue with some reflections on the gap between discourse on social participation and its inexistence. The goal is to elicit reflection that generates a polemic regarding the technical nature of the scientific reports produced and thus be able to integrate the overriding question into the set of reflections: How can one plan more resilient locations that are simultaneously socially equitable, have economic vitality, are environmentally compatible and less vulnerable to disasters? The reflections are the result of the analysis of technical and scientific documents.
\end{abstract}

Key words Disasters, Social exclusion, Public policy, Participation
Resumo Ao destacar o evento-extremo de 11-12 de janeiro de 2011, nas cidades serranas do estado do Rio de Janeiro, Brasil, quer-se exemplificar paradigmaticamente a tríade: problemas contemporâneos/inadaptação governamental/baixa participação pública, e apontar reflexões sobre o fosso entre o discurso pela participação social e a sua inexistência. O objetivo é produzir reflexão que polemize a tecnicidade dos relatórios científicos produzidos e, dessa forma, ser capaz de integrar, ao conjunto de reflexões, a questão maior: como se pode planejar lugares mais resistentes que sejam, simultaneamente, socialmente justos, apresentem vitalidade econômica, sejam ecologicamente compatíveis, e menos vulneráveis a desastres? As reflexões são resultados da análise de documentos técnico-científicos.

Palavras-chave Desastres, Exclusão social, Políticas públicas, Participação 


\section{Introdução}

A partir do evento-extremo de 11-12 de janeiro de 2011, nas cidades serranas do estado do Rio de Janeiro, Brasil, este artigo pretende exemplificar as dificuldades em lidar com a tríade: gestão governamental/conhecimento técnico-científico/ cidadãos-públicos. Essa relação poder-conhecimento-população é refletida e multiplicada em todas as áreas da administração estatal, mais especificamente em eventos extremos, que se expõe através de inúmeras controvérsias públicas e abrem-nos espaço para a polemização da tecnicidade da maioria dos relatórios produzidos sobre o evento, e que aqui são submetidos a uma primeira discussão.

Problemas mundializados e inadaptação dos governos a estes têm vindo a conferir à participação social um valor que alguns designam de míti$\mathrm{Co}^{1}$. A dinamização da participação seria a panaceia que resolveria as dificuldades crescentes, da parte dos governos, de gestão de dinâmicas sociais cada vez mais complexas e incertas. Mesmo que referendada em todos os discursos e textos de referência de políticas públicas, e em muitos casos promovendo uma sintaxe própria como nos manuais de organismos internacionais como ONU, OMS e Banco Mundial, hoje ainda não se sabe como tornar a participação social impactante na resolução dos problemas mundializados e na superação da inadequação das respostas dos governos aos mesmos ${ }^{2-5}$.

A escolha de discutir o tema da relação governo-ciência-cidadãos em eventos extremos não é, assim, ocasional ou, paradoxalmente, evidente. Mas parece que as características que em situações não extremas são quase invisíveis, naturalizadas, classificada de normais, ficam expostas e exacerbadas em situações de crise social, produzindo exclusão daqueles que alegadamente se quer incluir ${ }^{6}$.

Mas o que está normalizado - naturalizado - na relação governo-ciência-cidadãos durante eventos extremos? Está aceito que o sistema de redução de desastres é inevitável, necessário e consequentemente benigno - é politicamente desejável, e existe para preservar, salvar e recuperar vidas. Descrito a este nível de generalidade, parece ser uma exigência indiscutível. Porém, há muito mais filigranas éticas do que poderia se supor a partir da afirmação anterior, e que não podem ser desconsideradas, justamente por estar em jogo o valor da vida humana. E o valor da vida humana, como destaca Enrique Dussel ${ }^{7}$ em suas seis teses, nunca pode ser considerada sem a sua relação com o valor liberdade humana. Portanto, a necessidade de preservar a vida e promovê-la em liberdade é uma condição antecedente e necessária que justifica a resposta aos desastres, mas que não legitima necessariamente o sistema de prevenção e redução de desastres e seus efeitos que está sendo organizado, mundialmente e localmente, de maneira intensiva.

Assim como as sociedades modernas, os sistemas de redução de desastres, sejam plataformas locais, nacionais ou internacionais, já nascem saturados de ciência e tecnologia, a que os cidadãos são expostos de diferentes formas e com a qual se relacionam de maneiras distintas. Uma das características mais marcantes destas sociedades é a separação entre a necessidade de compreender como funcionam as tecnologias e as competências para utilizar as mesmas. No pós- guerra, a crença imediata dos governos e dos formuladores de políticas públicas era que a existência de especialistas com credenciais científicas e técnicas (médicos, engenheiros, gestores, etc.) asseguraria a mediação adequada a essa situação. A relação entre ciência/conhecimento especializado e Estado assumiu, nas sociedades do Norte, a forma de uma "dupla delegação" dos cidadãos nos políticos e funcionários do Estado para a administração da coisa pública e nos cientistas e peritos para a administração das questões científicas e técnicas com implicações para a vida social ${ }^{8}$.

No entanto, ao longo das últimas décadas do século XX, sucederam-se as crises associadas a problemas em que os conhecimentos disciplinares, as ciências e as tecnologias desempenham um papel central - mudanças climáticas globais, resíduos nucleares, resíduos industriais e urbanos, segurança alimentar, AIDS, doenças emergentes, sangue contaminado, organismos geneticamente modificados, clonagem, exclusão social, dependência química, entre outros. O tipo de sociedade daí resultante, designada por Beck" de "sociedade de risco" tenderia a ser global, na medida em que os novos riscos não reconhecem fronteiras.

A tese da "sociedade de risco" sofreu muitas críticas, de conteúdo diverso, mas a mais importante para o estudo das transformações nos modos de governar as sociedades contemporâneas é a da falta de compreensão do jogo de continuidades e descontinuidades entre a biopolítica e as respostas políticas às crises que ameaçavam a eficácia e legitimidade da "dupla delegação". No caso dos sistemas de redução de desastres (aparentemente o tema mais próximo de Beck ${ }^{9}$ ), essa falta se transforma em uma inoperância compreensiva quando se territorializa a generalidade da tese da 
sociedade de risco, principalmente nos países do Sul e entre populações para além da linha abissal, como definido por Boaventura de Sousa Santos ${ }^{10}$. Nesse sentido, um esforço para a compreensão do enfrentamento entre a dupla delegação e as ações coletivas baseadas no território, no local, faz-se necessário. Podemos distinguir quatro modos principais de envolvimento dos cidadãos com as ciências e os conhecimentos especializados: Exterioridade (delegação incondicional de autoridade e de competência aos cientistas e peritos credenciados); Alinhamento (os cidadãos adotam as posições dos especialistas e subscrevem a legitimidade dos seus procedimentos); Resistência (associada à crítica explícita do conhecimento científico e especializado e dos seus porta-vozes); e Articulação (reconhece a heterogeneidade dos atores e dos modos de conhecimento envolvidos; promove a procura e a construção ativa de novas configurações de conhecimentos e de modos de intervenção, de alinhamentos de atores e de constituição de sujeitos; abre espaços para a emergência de ecologias de saberes ${ }^{11}$ e de formas de relação entre modos de conhecimento que evitam a desqualificação mútua).

Esta classificação tem um caráter ideal-típico. De fato, os mesmos atores podem, em contextos diferentes ou quando confrontados com conhecimentos distintos, adotar modos de envolvimento diversos, e é possível passar de um para outro modo no decorrer dos próprios processos de envolvimento. No entanto, em eventos extremos no encontro do sistema de redução de desastres duplamente delegado - e descrito como um conjunto de ações integradas pela prevenção, resposta e recuperação ao evento, o modo articulação só se manifesta rapidamente na resposta ao desastre, no encontro da solidariedade dos cidadãos, das comunidades, incluindo a científica e o próprio governo, e a sociedade. $\mathrm{Na}$ fase de recuperação, em países do Sul, o retorno ao modo exterioridade costuma seguir-se, podendo converter-se numa posição de alinhamento. Nos processos de prevenção, o fenômeno se repete. Ironicamente, é onde o conceito de resiliência melhor pode ser aplicado: o retorno da relação governo-ciênciacidadãos à posição anterior ao desastre.

No verão de 2011, na região serrana do Rio de Janeiro, Brasil, houve a atualização do risco existente naquela área consubstanciada por um evento-extremo inesperado de chuvas fortes, em terras de altitudes médias entre 650 metros e 1.100 metros. Durante cinco horas, na passagem de 11 para 12 de janeiro de 2011, a chuva alcançou a intensidade de $130 \mathrm{~mm} /$ hora, gerando o transbordamen- to de todos os rios da região serrana e arredores e que integram a bacia do rio Paraíba do Sul. Essa precipitação produziu mais de 750 deslizamentos de terra em uma área de cerca de 350 quilômetros quadrados, com a média impressionante de mais de dois desabamentos por quilômetro quadrado. O número de mortes chegou a mais de mil pessoas (909 corpos resgatados e oficialmente reconhecidos e 241 pessoas não encontradas). Foram estimados danos superiores à ordem de um bilhão de reais (mais de US\$ 700 milhões) ${ }^{12,13}$.

Diferentes documentos oficiais sobre a análise dos acontecimentos de janeiro de $2011^{14-18}$ revelam um incômodo consenso sobre os fatores determinantes do desastre: primeiro, o próprio evento meteorológico, associado às características geoambientais da região. Segundo, um conjunto de problemas ligados ao ordenamento territorial, como a política dos usos de solos e o crescimento urbano descontrolado. E, terceiro, a falta de planos de prevenção e emergência locais. Todos esses fatores, em conjunto, teriam criado um ambiente de difícil gestão naquela noite de janeiro de 2011.

A inexistência de planos de contingência, hoje, no Brasil, é um fato que, nas cidades serranas, tem o seu exemplo mais trágico. Sem seus planos locais de prevenção e emergência, a população ficou refém das ações espontâneas externas, estaduais, federais ou humanitárias. Tais ações, realizadas por sua necessidade evidente, não deixaram, no entanto, de excluir a própria população enquanto comunidade que decide sobre sua vida e organização. O sistema municipal ficou exposto em sua ineficiência, até atingir, nos meses posteriores ao evento, níveis de desagregação inimagináveis, com a destituição dos prefeitos tanto em Teresópolis como em Nova Friburgo, por improbidade administrativa, fraude e corrupção.

No entanto, paralelamente, várias centenas de voluntários e organizações se mobilizaram desenvolvendo ações de assistência pública. Inúmeras redes de apoio se formaram espontaneamente através das redes sociais e de sites e blogues. Esse encontro entre instituições públicas, organizações da sociedade civil e o conjunto da população, em um evento-extremo, é uma das positividades que podem emergir da situação do evento -extremo. A solidariedade flui e a colaboração e a participação social se materializam no dia-a-dia. No entanto, se o sistema público - principalmente local - não está preparado para suportar (com todos os significados do termo) tal encontro, este não reúne condições para a sua continuidade e se desfaz rapidamente. 
No caso das cidades serranas, as ações governamentais e humanitárias, e apesar da sua intenção explícita de acorrer às populações atingidas pelo evento, acabariam por confirmar a ausência de reconhecimento da capacidade das populações para se organizarem e assumirem como protagonistas da resposta ao evento e às suas consequências.

Diante de tantas lacunas nas políticas públicas, e de numerosos problemas de complexa resolução, é muito curioso o quão pouco se produziu cientificamente sobre o assunto. Tão vulnerável quanto populações e programas de políticas públicas, também aí está a produção de conhecimento científico para a área de riscos e desastres no Brasil. Uma hipótese plausível para dar sentido a esse estado de coisas é a de que o consenso entre autoridades e pesquisadores sobre o despreparo da sociedade brasileira - e principalmente de seus governos - para responder às situações de emergência e de desastre é tão forte que a discussão em torno dos riscos e desastres existe, mas acaba confinada ao universo da "dupla delegação".

Esse evento extremo, contudo, acelerou processos de mudanças nas máquinas governamentais, modificando-as em várias direções e promovendo, inclusive, o surgimento inesperado de novos organismos. A criação do Cemaden (decreto 7.513, de primeiro de julho de 2011 Centro Nacional de Monitoramento e Alertas de Desastres Naturais) é um exemplo. Seguindo o Ministério da Ciência e Tecnologia, também foi criada no âmbito do Ministério da Saúde, a Força Nacional do Sistema Único de Saúde (Decreto ${ }^{\circ}$ 7.616, de 17 de novembro de 2011), que tem o objetivo de dar conta de, e apoio às emergências em todo o território nacional, na área de assistência de saúde e saúde pública. Neste torvelinho de mudanças, a Assembleia Nacional criou uma comissão para avaliar o aparato legal e a lei de desastres. Essa comissão gerou proposta de lei que foi discutida, modificada e promulgada sob o número 12.608 de 10 de abril de 2012, e que "institui a Política Nacional de Proteção e Defesa Civil - PNPDEC". No Estado do Rio, para além do esforço de produção de mapas de riscos dos 92 municípios (hoje cobrindo 70\% do total, segundo fontes oficiais), foi construído um Centro de Operações estadual (informatizado e ligado em rede com todos os municípios), a exemplo daquele que foi construído exclusivamente para a cidade do Rio de Janeiro. A cidade do Rio é um exemplo de discussões e investimentos nas áreas de segurança e risco. Uma integralidade que no governo federal, apesar da disponibilidade de recursos, ainda não é vista. Para apoiar o Cemaden como um Sistema de Alerta mínimo, o CENAD (Centro Nacional de Gerenciamento de Riscos e Desastres do Ministério da Integração Nacional) foi reaparelhado e remontado em nova área para receber as avaliações do Cemanden e repassá-la ao restante das defesas civis estaduais e instituições interligadas para o resto do país. Tudo isso faz parte do Plano Nacional de Gestão de Riscos e Resposta a Desastres Naturais 2012-2014, lançado durante a inauguração do novo CENAD pela presidente Dilma.

A desvalorização desse impacto administrativo nas discussões sobre a gestão do risco, seja pelos relatórios técnicos ou por artigos científicos, aponta para três direções: (1) Considerando a dimensão do Brasil, as ações ainda são limitadas dentro dos vários níveis de governo e não têm a devida racionalidade de sistema que a área de riscos e desastres exige; (2) dessa forma, o tema não ganha a devida capilaridade e importância para os cidadãos, nem a devida transparência pública por parte dos governos; e (3), portanto, o tema permanece uma agenda menor dentro da máquina estatal - em que o principal indicativo é a nova Lei 12.608 , que não institui um fundo regular para financiamento das ações, como existe no Sistema Único de Saúde, na Educação, ou mesmo no sistema de Ciência e Tecnologia. Na prática, a responsabilidade quase integral - e sua impossibilidade - por pagar a conta da organização do sistema de prevenção em nível local ficou na mão dos municípios.

Esse foi o grande impacto para além das serras fluminenses. Mas o que isso significou para a população desses territórios até o momento (ou para qualquer outra comunidade no Brasil ou para a população brasileira como um todo)? Não muito. Sem capilaridade, o financiamento do sistema de proteção civil não chega até a população, seja como prevenção, seja como recuperação, e certamente não como resposta eficiente.

No evento aqui estudado, essa situação de exclusão foi aprofundada pela internacionalização do evento-extremo e a sua valorização na mídia internacional que o associou aos fenômenos das mudanças climáticas. O interesse do Banco Mundial lembra a imagem utilizada por Boaventura Santos ${ }^{10}$ do encontro entre o tecnocrata do Banco Mundial e o agricultor da savana africana, que pela lógica capitalista, os transforma em seres de épocas diferentes no mesmo presente. Expropriado de sua própria história e valor, o agricultor não tem nada a acrescentar sobre a sua situação, 
a sua experiência e a sua história aos relatórios atualizados do tecnocrata globalizado. A semelhança dessa imagem com a tentativa de se promover a visita do presidente de Banco Mundial às cidades serranas é sugestiva. As rotas a seguir pelo seu helicóptero chegaram a ser traçadas e toda a logística de segurança instalada. No momento da visita, a diretoria optou por manter o encontro com a presidente Dilma e garantir a divulgação na mídia do seu empréstimo para as obras de contenção e drenagem. Mas, o essencial foi feito, o evento-extremo das cidades serranas foi integrado ao referencial internacional defendido pelo Banco Mundial de que estamos diante de uma revolução do sistema ecológico mundial, justificando as estratégias internacionais de intervenção econômica para a prevenção do risco. Através desta ação, a população das cidades serranas acabou sendo como que excluída de seu próprio desastre, que agora passa a figurar como exemplo planetário das mudanças climáticas.

Esse conjunto de ações-manobras faz com que a população seja desapropriada da capacidade de lidar com a experiência de seu desastre, como nas fábricas fordistas do início do século passado, em que, pela aplicação da administração científica do trabalho de Taylor ${ }^{19}$, o conhecimento comunitário, local, e pessoal vai sendo extraído e impessoalizado em relatórios e registros técnico-científicos. Canguilhem destaca o absurdo da situação:

O que escapou aos psicólogos da enquête de Hawthorne é que os operários não tomariam como autenticamente normais senão as condições de trabalho que eles mesmos teriam instituído em referência a valores próprios e não emprestados, e que o meio de trabalho que eles tomariam como normal seria aquele que eles teriam feito eles mesmos, a eles mesmos, para eles mesmos. Todo homem quer ser sujeito de suas normas. A ilusão capitalista está em acreditar que as normas capitalistas são definitivas e universais, sem pensar que a normatividade não pode ser um privilégio ${ }^{19}$

Existe um volume considerável de informação, de âmbito internacional, sobre políticas públicas para a área de risco e desastres, que pode ser acessada, por exemplo, através dos sites da ONU relacionados à Estratégia Internacional de Redução de Desastres. Aí se encontram listas organizadas de normas para ações públicas coerentes, como a lista básica de um supermercado, sugerindo que basta segui-la para que se possa atuar de forma adequada. No entanto, não basta comprá-la - supondo que se tem os recursos disponíveis para isso - pois, na prática, há muito mais aspectos envolvidos do que a sua aplicação. É preciso desenvolver algo que não se esgota em uma lista qualquer de ação governamental e que, no momento, não se sabe bem como fazer. Como responder, então, perante a pressão de um evento-extremo, ao imperativo de respeito pelas dinâmicas relacionais que são a condição da resiliência das populações atingidas, e pela sua capacidade de se organizarem para a resposta ao evento? E como promover a dinâmica de solidariedade da sociedade para com os que foram atingidos? Essa dinâmica manifestou-se, por exemplo, nos dias posteriores ao desastre serrano, pela solidariedade voluntária expressa nas redes sociais digitais e concretizadas em recursos materiais e humanos destinados aos concidadãos atingidos. O desenvolvimento e a universalização da internet e de suas redes de compartilhamento de informações e interesses, com as chamadas redes sociais, poderão oferecer recursos inovadores para a mobilização da sociedade, mas a sua conversão em ações eficazes de intervenção junto das populações atingidas exige a criação de agenciamentos que permitam articulações entre instituições públicas e a ação coletiva dessas populações.

Existe um pensamento basal que pode ser nosso maior obstáculo e que está expresso de maneira brilhante por Canguilhem ${ }^{19}$ na citação acima destacada: é que a ciência ("os psicólogos de Hawthorne”) está interligada e a serviço do poder (“ilusão capitalista”). Essa configuração de poder/saber, nas suas respostas aos desastres e eventos-extremos, tende a promover normas universais, como as que são propostas por organizações internacionais, ignorando que "todo homem quer ser sujeito de suas normas". Por isso, os sistemas existentes, ao relacionar-se com os cidadãos, tanto em períodos de "normalidade" como em tempos de perturbação, como os que são marcados por eventos-extremos de política pública, têm tanta dificuldade em reconhecer que, mesmo em situações de ameaça e de grande vulnerabilidade, os cidadãos são capazes de mobilizar as suas experiências, saberes e capacidades para agir coletivamente, tanto na prevenção como na resposta. O resultado é o silenciamento e a invisibilização das suas dinâmicas relacionais, a transformação das populações em objetos de intervenções institucionais.

As políticas públicas de redução de riscos devem visar, numa sociedade democrática, a realização da segurança, da saúde e da sustentabilidade. É duvidoso que a normatização excludente incorporada em intervenções que ignoram as dinâmicas locais e as capacidades dos cidadãos para 
a ação coletiva contribua para a realização desses objetivos. As consequências dos eventos-extremos não decorrem (apenas) da imprevisibilidade ou incontrolabilidade dos fenômenos, mas do modo como se distribui entre populações, classes sociais e comunidades. Uma vulnerabilidade que é gerada e alimentada por um capitalismo global que já tem sido designado de "capitalismo de desastre"20. As políticas públicas converteram-se, por isso, em arenas onde se joga a distribuição desigual da vulnerabilidade, da vida e da morte. O silenciamento e a invisibilização pela exclusão da participação aparece, assim, como uma nega- ção do princípio vida de que nos fala $\operatorname{Dussel}^{7}$, a condição primeira da possibilidade de qualquer forma de vida democrática.

\section{Colaboradores}

SLD Portella e JA Nunes participaram igualmente de todas as etapas de elaboração do artigo.

\section{Referências}

1. Milani C. O princípio da participação social na gestão de políticas públicas locais: uma análise de experiências latino-americanas e europeias. Rev. Administração Pública 2008; 42(3):551-579.

2. Porto M, Finamore R. Riscos, Saúde e Justiça Ambiental: o protagonismo das populações atingidas na produção de conhecimento. Cien Saude Colet 2012; 17(6):1493-1501.

3. United Nations Development Programme (UNDP). People's Participation Technical Report. New York: UNDP; 1993.

4. Cooke B, Kothari U, editors. Participation: The New Tyranny? London: Zed Books; 2001.

5. Hickey S, Mohan G, editors. Participation - From Tyranny to Transformation? Exploring New Approaches to Participation in Development. London: Zed Books; 2004.

6. Nunes JA. Governação, Conhecimento e Participação Pública. Relatório para Provas de Agregação. Coimbra: Faculdade de Economia da Universidade de Coimbra; 2007.

7. Dussel E. Six Theses toward a Critique of Political Reason. Radical Philosophy Review 1999; 2(2):75-95.

8. Callon M, Lascoumes P, Barthe Y. Agir dans un monde incertain. Essai sur la démocratie technique. Paris: Seuil; 2001.

9. Beck U. Risk Society: Towards a New Modernity. London: Sage; 1992.

10. Santos BS. Para além do Pensamento Abissal: das linhas globais a uma ecologia de saberes. Rev. Crítica de Ciências Sociais 2007; 78:3-46.

11. Santos BS. A gramática do tempo: para uma nova cultura política. Porto: Afrontamento; 2006.

12. Freitas C, Carvalho M, Ximenes E, Arraes E, Gomes J. Vulnerabilidade Socioambiental, Redução de Riscos de Desastres e Construção da Resiliência - lições do terremoto no Haiti e das chuvas fortes na Região Serrana, Brasil. Cien Saude Colet 2012; 17(6):1577-1586.

13. Medeiros V, Barros M. Análise de eventos críticos de precipitação ocorridos na região serrana do estado do Rio de Janeiro nos dias 11 e 12 de janeiro de 2011. In: Anais do XIX Simpósio Brasileiro de Recursos Hídricos; 2011; Maceió.
14. Conselho Regional de Engenharia e Agronomia (CREA-RJ). Relatório preliminar da inspeção realizada em áreas de Teresópolis e Nova Friburgo afetadas pelas fortes chuvas em Janeiro de 2011. Rio de Janeiro: CREA; 20011.

15. Conselho Regional de Engenharia e Agronomia (CREA-RJ). Relatório - Tragédia na Região Serrana do Rio de Janeiro após decorridos 6 meses. Rio de Janeiro: CREA; 2011.

16. Conselho Regional de Engenharia e Agronomia (CREA-RJ). Terceiro relatório de inspeção a região serrana do Estado do Rio de Janeiro - um ano após a tragédia ocorrida em Janeiro de 2011. Rio de Janeiro: CREA; 2012.

17. Rio de Janeiro. Resolução $\mathrm{n}^{\circ} 9$, de 8 de fevereiro de 2011. Comissão parlamentar de inquérito para investigar as circunstâncias, os fatos, as possíveis omissões, negligencias, imprevidências e averiguar possíveis responsabilidades de agentes políticos, públicos e de terceiros, em face do desastre ocorrido nos municípios da região serrana do estado do Rio de Janeiro decorrente das fortes chuvas que causaram inundações e deslizamentos de encostas no período de 11 e 12 de Janeiro de 2011. Diário Oficial do Estado do Rio de Janeiro 2011; 15 set.

18. Brasil. Ministério do Meio Ambiente (MMA). Área atingida pela tragédia das chuvas, Região Serrana do Rio de Janeiro. Áreas de Preservação Permanente e Unidades de Conservação \& Áreas de Risco: o que uma coisa tem a ver com a outra? Relatório de Inspeção. Brasília: MMA; 2011.

19. Canguilhem G. Meio e normas do homem no trabalho. Pro-posições 2001; 12(2-3):109-121.

20. Klein N. The Shock Doctrine: The Rise of Disaster Capitalism. New York: Picador; 2007.

Artigo apresentado em 06/07/2014

Aprovado em 17/07/2014

Versão final apresentada em 18/07/2014 